\title{
FACTORS ASSOCIATED WITH TOTAL HIP AND KNEE ARTHROPLASTY OUTCOMES
}

\author{
Safa Ghanghermeh ${ }^{1}$, Seyed Mohammad Reza Esmaeilnejad-Ganji2, Masoud Bahrami3 , Soraya Khafri ${ }^{4}$, \\ Seyed Mokhtar Esmaeilnejad-Ganji ${ }^{5}$
}

1MD, Student Research Committee, School of Medicine, Babol University of Medical Sciences, Babol, Iran. 2MD, Boston University School of Medicine, Boston, USA.

${ }^{3}$ Assistant Professor, Department of Orthopaedics, Babol University of Medical Sciences, Babol, Iran.

${ }^{4}$ Assistant Professor, Biostatistics and Epidemiology Department, Medicine Faculty, Babol University of Medical Sciences, Babol, Iran. ${ }_{5}^{5}$ Associate Professor, Clinical Research Development Centre, Shahid Beheshti Hospital, Babol University of Medical Sciences, Babol, Iran.

\section{BACKGROUND}

\section{ABSTRACT}

Total joint replacement is potentially an effective option for treatment of patients in the end-stage arthritis. Limited data exists about the outcome of this surgery and the related factors in Iran.

Aim- The purpose of this study was to assess the total hip and knee arthroplasty outcome and its predictors in northern Iran.

\section{MATERIALS AND METHODS}

In this prospective observational study, we included the patients who underwent total hip and knee arthroplasty during 20142017 and 2015-2017, respectively, in Rohani and Shahid Beheshti Teaching Hospitals affiliated to Babol University of Medical Sciences. To investigate the hip and knee function following the surgeries, we used the Knee Society Score and Harris Hip Score, respectively. Higher scores show better status. Post-operative complications were also recorded. We evaluated the patients' scores before the operation and twelve weeks post-operatively. Patients' characteristics were collected by a checklist.

\section{RESULTS}

In this prospective observational study, a total of 200 patients were enrolled, of whom 70 (35\%) underwent total knee arthroplasty and $130(65 \%)$ underwent total hip arthroplasty. Eighty-eight (44\%) patients were men and others were women. The mean age was $58.07 \pm 15.19$ (ranging from 18 - 88) years old. The mean Knee Score before total knee arthroplasty was $29.4 \pm 74.12$, progressed to $81.9 \pm 36.59$ after 12 weeks ( $<<0.001$ ). About the mean Harris Hip Score, it was $51.71 \pm 7.94$ before total hip arthroplasty, improved to $82.64 \pm 5.61$ after 12 weeks ( $\mathrm{p}<0.001)$. Most of the patients $(\mathrm{n}=181,90.5 \%)$ did not experience any postoperative complications and infection was the most frequent complication (8 patients). According to the analyses, there were no significant relationships between the different factors including age, sex, marital status, occupation, educational level and body mass index and Harris Hip score and Knee score.

\section{CONCLUSION}

Both total hip and knee arthroplasties were safe procedures with high rate of satisfaction and low rate of complications. By the way, demographic variables did not significantly affect the surgery's outcome.

\section{KEY WORDS}

Hip Joint, Knee Joint, Arthroplasty, Replacement, Outcome, Risk Factor.

HOW TO CITE THIS ARTICLE: Ghanghermeh S, Ganji SMRE, Bahrami M, et al. Factors associated with total hip and knee arthroplasty outcomes. J. Evolution Med. Dent. Sci. 2018;7(48):5154-5158, DOI: 10.14260/jemds/2018/1144

\section{BACKGROUND}

Hip arthroplasty is a method, in which the hip joint is replaced by a prosthetic implant. This procedure is done partially and totally. In total hip arthroplasty both of acetabulum and femoral head will be replaced, but in the partial method femoral head is usually replaced. Hip arthroplasty is used for treatment of hip osteoarthritis, traumatic bone fractures, avascular necrosis and other similar joint diseases.

'Financial or Other Competing Interest': Dr. Esmaeilnejad-Ganji reports grants from Vice Chancellor for the Research, outside the submitted work.

Submission 17-10-2018, Peer Review 12-11-2018,

Acceptance 19-11-2018, Published 26-11-2018.

Corresponding Author:

Dr. Seyed Mokhtar Esmaeilnejad-Ganji,

Department of Orthopaedics,

Babol University of Medical Sciences,

Ganjafrooz Street, Babol,Mazandaran, Iran

E-mail: smsnganji20@gmail.com

DOI: $10.14260 /$ jemds/2018/1144
Today, total hip arthroplasty is one of the most frequent surgeries in orthopaedics.(1,2) Knee arthroplasty is performed partially and totally as well. In this method, the damaged articular parts are replaced by metallic and plastic components to achieve the range of motion and increase pain. Total knee arthroplasty can be used as a therapeutic method in the patients with osteoarthritic, rheumatoid arthritis, psoriatic arthritis and knee deformities.(3-6)

Use of total joint replacements is increasing today. Based on a report in 2010, 71021 and 79263 surgeries were recorded for total hip and knee arthroplasty, respectively. These rates in America in 2006 were 231000 and 542000 surgeries, respectively, showing high records.(7)

Post-operative complications for total hip and knee arthroplasty are similar. Infection is the most important complication. Others included joint dislocation, bone fractures and prosthesis, deep venous thrombosis, nerve injury and remained pain. (8-10) 
It was reported that some factors can affect the surgery outcomes including demographic (Age, sex, ethnicity), social behaviours (Occupation, smoking, exercise), associated disease (Rheumatoid arthritis, diabetes) and place of health service reception (Governmental/ Private hospitals, trainings after the discharge).(11,12)

Considering the increasing trend in total hip and knee replacements and the serious post-operative complications and also given the limited information on the outcomes of the two surgeries in Iran, we aimed to assess the results of the total hip and knee arthroplasty and the related factors in north of Iran. These results would be helpful for the patients suffering from hip and knee degenerative diseases to be relieved from pain and dependence.

\section{MATERIALS AND METHODS}

In this prospective observational study, we prospectively enrolled the patients who underwent total hip and knee arthroplasty during 2014-2017 and 2015-2017, respectively. The surgeries were conducted in Rohani and Shahid Beheshti Teaching Hospitals affiliated to Babol University of Medical Sciences. We excluded the patients with previous knee arthroplasty and/ or contraindication for major surgeries. Those patients who failed to follow-up were also excluded.

We collected the necessary data from the individuals including demographic (Age, sex, marital status, occupation, educational level and body mass index), surgery duration and post-operative complications. The data were obtained by a checklist.

In order to evaluate the hip function, the Harris Hip Score was used. This scale has a maximum of 100 points, evaluating pain (0 - 44 scores), patient's function during various activities ( 0 - 47 scores), the deformity level (4 scores) and hip range of motion (5 scores). Scoring range of $90-100$ is considered an excellent result, 80 - 89 is good, $70-79$ is fair, and $<70$ is poor.(13) To measure the knee function we used the Knee Society Score, which was initially released by the Knee Society in 1989.(3,14) The knee score contains three items with specific scoring system including pain (50 scores), range of motion (25 scores) and joint stability (25 scores). Joint stiffness in bending, inability to open knee and poor knee alignment have negative scores. Totally, scores are rated excellent (80 - 100), good (70 - 79), fair (60 - 69) and poor $(<60)$. We assessed the patients' scores before the operation and twelve weeks post-operatively.

Before starting the study, we explained the study aims to the subjects and then written informed consent was obtained. The reassurance was given to the patients about the surgical care, pain control and post-operative analgesia, and home discharge as soon as possible after the surgery. The indication for total hip and knee arthroplasty was determined by the orthopaedic surgeon. The necessary x-ray radiographs were taken for all patients. Antibiotic Keflin (500 mg intravenously every 6 hours) was administered to the patients pre-operatively as prophylaxis. All surgeries were conducted by the same senior orthopaedic surgeon. Total knee arthroplasty lasts 45 - 120 minutes. This duration was 45 - 90 minutes for total hip arthroplasty. All knees got the same prosthesis. Regarding total hip arthroplasty, all implants had a standard cementless cup and a cementless stem. The implants used for total knee arthroplasty included femoral and tibial components and polyethylene insert.
Until the first 48 hours of surgery, cefazolin $1 \mathrm{~g}$ intravenously every 6 hours was administered. We also administered acetaminophen every 12 hours to control the post-operative pain. Two days after the surgeries, the patients should be out-of-bed. In relation to total hip arthroplasty, the patients were encouraged to begin walking and physiotherapy. Patients underwent total knee arthroplasty, performed range of motion exercises as passive and active flexion and extension.

The data were collected and analysed by SPSS software using descriptive analysis. Also, paired t-test and ANOVA analysis were used to compare the mean Harris Hip Score and Knee Score between different categories. A p $<0.05$ was taken as statistically significant.

The study protocol was approved by the Ethical Committee of Babol University of Medical Sciences (code: MUBABOL.HRI.REC.1395.59). We collected the informed consent from the subjects. The patients' information were kept confidential.

\section{RESULTS}

In this prospective observational study of 200 patients were finally included, of whom 130 (65\%) underwent total hip arthroplasty and 70 (35\%) underwent total knee arthroplasty. Eighty-eight (44\%) patients were men and others were women. The mean age was $58.07 \pm 15.19$ years old, ranging from 18 to 88 years old. The demographic information of the patients underwent hip and knee arthroplasty. They were separately summarised in Table 1.

The mean Harris Hip Score before total hip arthroplasty was $51.71 \pm 7.94$, improved to $82.64 \pm 5.61$ after 12 weeks $(\mathrm{p}<0.001)$. Based on the total Harris Hip Score classification, after 12 weeks of surgery $45(35.6 \%)$ patients had an excellent status, 74 (56.9\%) patients had a good status and $11(8.5 \%)$ patients had a weak status. The mean knee score before total knee arthroplasty was $29.4 \pm 74.12$, progressed to $81.9 \pm 36.59$ after 12 weeks ( $<<0.001)$. According to the total Knee Society Score after 12 weeks of surgery, 27 (38.5\%) patients had an excellent outcome, 35 (50\%) had a good outcome, $6(8.6 \%)$ had a fair outcome and $2(2.6 \%)$ had a weak outcome. Most of the patients $(n=181,90.5 \%)$ did not experience any post-operative complications and infection was the most frequent complication (8 patients).

Table 2 shows the results of evaluation of the association between the different factors including age, sex, marital status, occupation, educational level and body mass index, and Harris Hip score and Knee Score. As indicated, no significant relationship was found after analyses.

\begin{tabular}{|c|c|c|c|}
\hline Variables & $\begin{array}{c}\text { Total } \\
(\mathbf{n = 2 0 0 , \% )}\end{array}$ & $\begin{array}{c}\text { Total Knee } \\
\text { Arthroplasty } \\
(\mathbf{n = 7 0 , \% )}\end{array}$ & $\begin{array}{c}\text { Total Hip } \\
\text { Arthroplasty } \\
\text { (n=130, \%) }\end{array}$ \\
\hline \multicolumn{4}{|c|}{ Age (Years) } \\
\hline$\leq 40$ & $26(13)$ & - & $26(20)$ \\
\hline $41-60$ & $81(40.5)$ & $20(28.6)$ & $61(46.9)$ \\
\hline$\geq 61$ & $93(46.5)$ & $50(71.4)$ & $43(33.1)$ \\
\hline \multicolumn{4}{|c|}{ Sex } \\
\hline Men & $88(44)$ & $15(21.4)$ & $73(56.2)$ \\
\hline Women & $112(56)$ & $55(78.6)$ & $57(43.8)$ \\
\hline
\end{tabular}




\begin{tabular}{|c|c|c|c|}
\hline \multicolumn{4}{|c|}{ Marital Status } \\
\hline Unmarried & $15(7.5)$ & $11(15.7)$ & $4(3.1)$ \\
\hline Married & $185(92.5)$ & $59(84.3)$ & $126(96.9)$ \\
\hline \multicolumn{4}{|c|}{ Occupation } \\
\hline Homemaker & $100(50)$ & $52(74.3)$ & $48(36.9)$ \\
\hline Self-Employed & $75(37.5)$ & $13(18.6)$ & $62(47.7)$ \\
\hline Retired & $8(4)$ & $2(2.9)$ & $6(4.6)$ \\
\hline Employee & $17(8.5)$ & $3(4.3)$ & $14(10.8)$ \\
\hline \multicolumn{4}{|c|}{ Educational Level } \\
\hline Illiterate & $96(48)$ & $31(44.3)$ & $65(50)$ \\
\hline Lower Diploma & $58(29)$ & $31(44.3)$ & $27(20.8)$ \\
\hline Diploma & $32(16)$ & $8(11.4)$ & $24(18.5)$ \\
\hline Higher Diploma & $14(7)$ & - & $14(10.8)$ \\
\hline \multicolumn{4}{|c|}{ Body Mass Index $\left(\mathrm{kg} / \mathrm{m}^{2}\right)$} \\
\hline$<18$ & $11(5.5)$ & $10(14.3)$ & $1(0.8)$ \\
\hline $18-24.9$ & $110(55)$ & $22(31.4)$ & $88(67.7)$ \\
\hline $25-29.9$ & $62(31)$ & $30(42.9)$ & $32(24.6)$ \\
\hline$\geq 30$ & $17(8.5)$ & $8(11.4)$ & $9(6.9)$ \\
\hline \multicolumn{4}{|c|}{ Table 1. Patients' Characteristics } \\
\hline
\end{tabular}

\begin{tabular}{|c|c|c|c|c|}
\hline Variables & 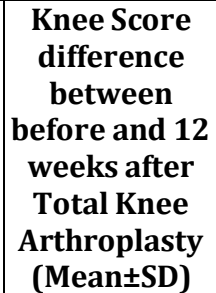 & value & $\begin{array}{c}\text { Harris Hip Score } \\
\text { difference } \\
\text { between before } \\
\text { and } 12 \text { weeks } \\
\text { after Total Hip } \\
\text { Arthroplasty } \\
\text { (Mean } \pm \text { SD) }\end{array}$ & P- \\
\hline \multicolumn{2}{|l|}{ Age (Years) } & \multirow{4}{*}{0.44} & & \multirow{4}{*}{0.15} \\
\hline$\leq 40$ & - & & $36.89 \pm 6.88$ & \\
\hline $41-60$ & $53.60 \pm 7.82$ & & $36.10 \pm 5.58$ & \\
\hline$\geq 61$ & $55.14 \pm 7.48$ & & $38.13 \pm 3.10$ & \\
\hline Sex & & \multirow{3}{*}{0.52} & & \multirow{3}{*}{0.61} \\
\hline Men & $55.80 \pm 8.70$ & & $36.72 \pm 5.00$ & \\
\hline Women & $54.40 \pm 7.27$ & & $37.19 \pm 5.60$ & \\
\hline $\begin{array}{c}\text { Marital } \\
\text { Status }\end{array}$ & & \multirow{3}{*}{0.13} & & \multirow{3}{*}{0.94} \\
\hline Unmarried & $51.54 \pm 7.71$ & & $37.12 \pm 8.59$ & \\
\hline Married & $55.28 \pm 7.45$ & & $36.92 \pm 5.17$ & \\
\hline \multicolumn{2}{|l|}{ Occupation } & \multirow{5}{*}{0.37} & & \multirow{5}{*}{0.11} \\
\hline Homemaker & $54.03 \pm 7.31$ & & $36.78 \pm 4.86$ & \\
\hline $\begin{array}{c}\text { Self- } \\
\text { Employed }\end{array}$ & $56.38 \pm 8.49$ & & $37.91 \pm 5.40$ & \\
\hline Retired & $52.00 \pm 12.72$ & & $35.32 \pm 3.23$ & \\
\hline Employee & $60.66 \pm 1.52$ & & $33.38 \pm 7.38$ & \\
\hline \multicolumn{2}{|l|}{$\begin{array}{c}\begin{array}{c}\text { Educational } \\
\text { Level }\end{array} \\
\end{array}$} & \multirow{5}{*}{0.38} & & \multirow{5}{*}{0.15} \\
\hline Illiterate & $56.09 \pm 8.49$ & & $37.48 \pm 5.22$ & \\
\hline $\begin{array}{c}\text { Lower } \\
\text { Diploma }\end{array}$ & $53.45 \pm 6.53$ & & $37.75 \pm 5.44$ & \\
\hline Diploma & $54.12 \pm 7.45$ & & $34.87 \pm 4.74$ & \\
\hline $\begin{array}{l}\text { Higher } \\
\text { Diploma }\end{array}$ & - & & $36.32 \pm 5.43$ & \\
\hline \multicolumn{2}{|l|}{$\begin{array}{c}\text { Body Mass } \\
\text { Index } \\
\left(\mathrm{kg} / \mathrm{m}^{2}\right)\end{array}$} & \multirow{5}{*}{0.50} & & \multirow{5}{*}{0.53} \\
\hline$<18$ & $51.80 \pm 5.11$ & & $35.50 \pm 4.00$ & \\
\hline $18-24.9$ & $55.18 \pm 9.38$ & & $34.37 \pm 5.49$ & \\
\hline $25-29.9$ & $54.66 \pm 7.09$ & & $36.36 \pm 4.93$ & \\
\hline$\geq 30$ & $57.12 \pm 6.10$ & & $35.28 \pm 3.95$ & \\
\hline \multicolumn{5}{|c|}{$\begin{array}{c}\text { Table 2. The Relationship between Predictors and Mean } \\
\text { Harris Hip Score and Knee Score }\end{array}$} \\
\hline
\end{tabular}

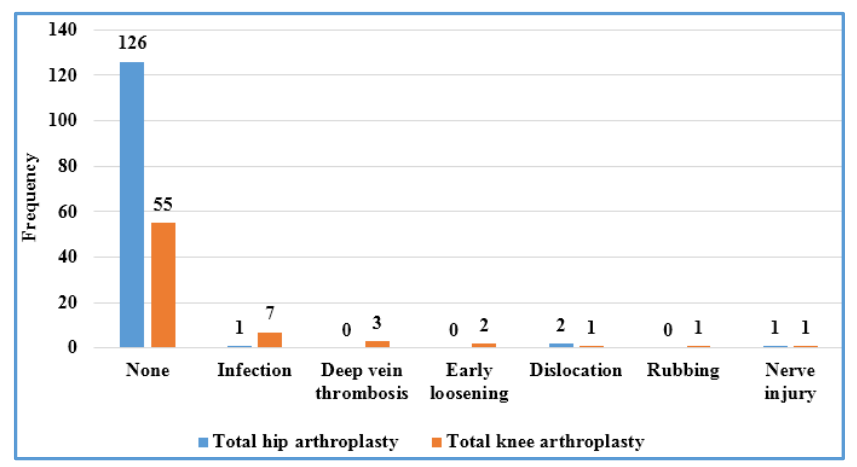

Figure 1. Post-operative Complications of Total Hip and Knee Arthroplasty

\section{DISCUSSION}

In this study, we firstly attempted to assess the outcomes of total hip and knee arthroplasty and secondly tried to find any potential factors related to the outcomes. In relation to the outcomes, we witnessed a significant improvement in the Knee Score and Harris Hip Score after the surgeries. These results were also observed in the previous studies as well. A recent systematic review on 95560 patients underwent total knee arthroplasty stated that $83 \%$ of the studies reported more than $80 \%$ satisfaction.(15) With increasing life expectancy, conduction of total knee and hip arthroplasty is rising too to improve the quality of life and movement. We also witnessed a low rate of post-operative complication for the two operations in our study, which was in agreement with the previous reports. $(16,17)$

In our study, no association was seen between age and surgery outcomes. Several studies reported that increasing age is associated with poorer functional outcome.(18,19) A study, for example, demonstrated that older patients had lower functional independent measure scores and efficiency than younger counterparts regardless of sex.(20) However, it is stated that long-term arthroplasty outcome is poorer in younger patients than in older ones, which is explained by high expectations and high physical demands on their prostheses. In majority studies, patients aged $<45$ years old had poorer prognosis compared with older patients.(21-23)

We found no significant relation between sex and arthroplasty outcomes. There were conflicting results about the effects of sex on the total joint arthroplasty. Some studies found better survival prosthesis and quality of life among women than men,(24-26) but others did not find sex difference in this regard.(27-29) On the other hand, a study alluded to better functional outcomes and daily living activity in men than in women. Besides, another survey stated that women had lower functional independent measure than men at admission and discharge.(20) Altogether, most of the reports revealed that being woman increase risk poor mobility after total joint arthroplasty.(20,30-32) Poorer functional outcome in women than in men can be due to lower limb strength and muscle tone and also because of differences in use of total joint replacement by men and women.(33) Of course, men are believed to have worse long-term outcomes secondary to harder occupational status and physical activity. However, more studies need to be conducted to clarify the effects on sex on total hip and knee arthroplasty outcomes. 
In this study, we found no significant relationship between body mass index and surgery outcomes. Bookman et al(34) declared that obese patients had a lower chance to be properly improved following total joint arthroplasty. These patients were also stated to tend to post-operative complications such as infection and dislocation, more than those patients with less body mass index. However, total joint arthroplasty is a beneficial approach for such patients to prevent their severe and progressive osteoarthritis. ${ }^{(34)}$

According to the previous studies, married patients were associated with better functional outcomes and lower rates of dislocation after joint arthroplasty. $(29,35)$ In fact, it can be said that patients who are married have better social support compared with those who are unmarried. Surgeries magnify the need for support in the short-term. Our results showed no significant association between marital status and arthroplasty outcomes. However, we suggest more studies about this subject.

Patients with higher educational level and an appropriate occupation and socioeconomic conditions are expected to have better surgery outcomes than those with poorer status, although we did not observe such a result in this study. A study expressed that patients with high school education or beyond had a better function following total hip arthroplasty than those with lower education level.(35) However, there are limited studies assessing the effect of education and occupation on joint arthroplasty outcomes and more investigations are proposed.

\section{CONCLUSION}

This study showed that total hip and knee arthroplasty were associated with good outcomes in the patients. Our results also indicated no significant relationship between variables including age, sex, marital status, occupation, educational level and body mass index, and outcomes of the joint replacements. It is suggested to design a study with longer period to assess, the long-term outcomes of the surgeries.

\section{ACKNOWLEDGEMENT}

The authors would like to thank the Vice Chancellor for the Research of Babol University of Medical Sciences for financial support. We also thank Ms. Sekineh Kamali Ahangar, member of Clinical Research Development Center of Shahid Beheshti Hospital, for her help in preparing the manuscript.

\section{REFERENCES}

[1] Cherubino P, Ratti C, Fagetti A, et al. Total hip arthroplasty and bone fragility. Aging Clin Exp Res 2011;23(2 Suppl):76-7.

[2] Lanting BA, Odum SM, Cope RP, et al. Incidence of perioperative events in single setting bilateral direct anterior approach total hip arthroplasty. J Arthroplasty 2015;30(3):465-7.

[3] Sassoon A, Nam D, Nunley R, et al. . Clin Orthop Relat Res 2015;473(1):151-8.

[4] Postler A, Lützner C, Beyer F, et al. Analysis of total knee arthroplasty revision causes. BMC Musculoskelet Disord 2018;19(1):55.

[5] Sukumarapillai S, Indulekha H. The association between body mass index and duration of spinal anaesthesia in adults undergoing total knee replacement arthroplasty - an observational study. J Evolution Med Dent Sci 2017;6(32):2665-9.

[6] Parvez A, Gyaneshwar T, Amit S, et al. Functional outcome of posterior stabilising total knee arthoplasty. J Evolution Med Dent Sci 2013;2(15):2417-25.

[7] Beswick AD, Wylde V, Gooberman-Hill R, et al. What proportion of patients report long-term pain after total hip or knee replacement for osteoarthritis? A systematic review of prospective studies in unselected patients. BMJ Open 2012;2(1):e000435.

[8] Leopold SS. Minimally invasive total knee arthroplasty for osteoarthritis. N Engl J Med 2009;360(17):174958.

[9] Ward DT, Metz LN, Horst PK, et al. Complications of morbid obesity in total joint arthroplasty: risk stratification based on BMI. J Arthroplasty 2015;30(Suppl 9):42-6.

[10] Hanjagi MY, Varkey P, Prakash V. Prospective study of efficacy of local infiltration analgesia and epidural analgesia in patients undergoing total knee replacements. J Evolution Med Dent Sci 2017;6(41):3214-8.

[11] SooHoo NF, Farng E, Lieberman JR, et al. Factors that predict short-term complication rates after total hip arthroplasty. Clin Orthop Relat Res 2010;468(9):236371.

[12] SooHoo NF, Lieberman JR, Ko CY, et al. Factors predicting complication rates following total knee replacement. J Bone Joint Surg Am 2006;88(3):480-5.

[13] Nilsdotter A, Bremander A. Measures of hip function and symptoms: Harris Hip Score (HHS), Hip Disability and Osteoarthritis Outcome Score (HOOS), Oxford Hip Score (OHS), Lequesne Index of Severity for Osteoarthritis of the Hip (LISOH), and American Academy of Orthopedic Surgeons (AAOS) Hip and Knee Questionnaire. Arthritis Care Res (Hoboken) 2011;63(Suppl 11):S200-S7.

[14] Insall JN, Dorr LD, Scott RD, et al. Rationale of the knee society clinical rating system. Clin Orthop Relat Res 1989;(248):13-4.

[15] Kahlenberg CA, Nwachukwu BU, McLawhorn AS, et al. Patient satisfaction after total knee replacement: a systematic review. HSS J 2018;14(2):192-201.

[16] Ravi B, Escott B, Shah PS, et al. A systematic review and meta-analysis comparing complications following total joint arthroplasty for rheumatoid arthritis versus for osteoarthritis. Arthritis Rheum 2012;64(12):383949.

[17] Parvizi J, Mui A, Purtill JJ, et al. Total joint arthroplasty: When do fatal or near-fatal complications occur? J Bone Joint Surg Am 2007;89(1):27-32.

[18] Santaguida PL, Hawker GA, Hudak PL, et al. Patient characteristics affecting the prognosis of total hip and knee joint arthroplasty: a systematic review. Canadian Journal of Surgery 2008;51(6):428-36.

[19] Newington DP, Bannister GC, Fordyce M. Primary total hip replacement in patients over 80 years of age. J Bone Joint Surg Br 1990;72(3):450-2. 
[20] Vincent HK, Alfano AP, Lee L, et al. Sex and age effects on outcomes of total hip arthroplasty after inpatient rehabilitation. Arch Phys Med Rehabil 2006;87(4):461-7.

[21] Severt R, Wood R, Cracchiolo A 3rd, et al. Long-term follow-up of cemented total hip arthroplasty in rheumatoid arthritis. Clin Orthop Relat Res 1991;(265):137-45.

[22] Sarmiento A, Ebramzadeh E, Gogan WJ, et al. Total hip arthroplasty with cement. A long-term radiographic analysis in patients who are older than fifty and younger than fifty years. J Bone Joint Surg Am 1990;72(10):1470-6.

[23] Boeree NR, Bannister GC. Cemented total hip arthroplasty in patients younger than 50 years of age. Ten-to 18-year results. Clin Orthop Relat Res 1993;(287):153-9.

[24] Schurman DJ, Bloch DA, Segal MR, et al. Conventional cemented total hip arthroplasty. Assessment of clinical factors associated with revision for mechanical failure. Clin Orthop Relat Res 1989;(240):173-80.

[25] Lachiewicz PF, McCaskill B, Inglis A, et al. Total hip arthroplasty in juvenile rheumatoid arthritis. Two to eleven-year results. J Bone Joint Surg Am 1986;68(4):502-8.

[26] Roush SE. Patient-perceived functional outcomes associated with elective hip and knee arthroplasties. Phys Ther 1985;65(10):1496-500.

[27] Weber M, Craiovan B, Woerner ML, et al. Predictors of outcome after primary total joint replacement. J Arthroplasty 2018;33(2):431-5.
[28] Kim YH, Kim VE. Uncemented porous-coated anatomic total hip replacement. Results at six years in a consecutive series. J Bone Joint Surg Br 1993;75(1):613.

[29] Cleary PD, Reilly DT, Greenfield S, et al. Using patient reports to assess health-related quality of life after total hip replacement. Qual Life Res 1993;2(1):3-11.

[30] Judge A, Javaid MK, Arden NK, et al. Clinical tool to identify patients who are most likely to achieve long-term improvement in physical function after total hip arthroplasty. Arthritis Care Res (Hoboken) 2012;64(6):881-9.

[31] Röder C, Parvizi J, Eggli S, et al. The frank stinchfield award: demographic factors affecting long-term outcome of total hip arthroplasty. Clin Orthop Relat Res 2003;417:62-73.

[32] Clayer MT, Bauze RJ. Morbidity and mortality following fractures of the femoral neck and trochanteric region: analysis of risk factors. J Trauma 1989;29(12):1673-8.

[33] Hawker GA, Wright JG, Coyte PC, et al. Differences between men and women in the rate of use of hip and knee arthroplasty. N Engl J Med 2000;342(14):101622.

[34] Bookman JS, Schwarzkopf R, Rathod P, et al. Obesity: the modifiable risk factor in total joint arthroplasty. Orthop Clin North Am 2018;49(3):291-6.

[35] Greenfield S, Apolone G, McNeil BJ, et al. The importance of co-existent disease in the occurrence of postoperative complications and one-year recovery in patients undergoing total hip replacement. Comorbidity and outcomes after hip replacement. Med Care 1993;31(2):141-54. 